\title{
ESTIMATING NEW PRODUCT SUCCESS WITH THE USE OF INTELLIGENT SYSTEMS
}

\author{
Marcin RELICH*, Krzysztof BZDYRA** \\ *Faculty of Economics and Management, University of Zielona Góra, Zielona Góra, Poland \\ e-mail:m.relich@wez.uz.zgora.pl \\ **Faculty of Electronic and Computer Engineering, Koszalin University of Technology, Koszalin, Poland \\ e-mail: krzysztof.bzdyra@tu.koszalin.pl
}

\begin{abstract}
The paper presents identifying success factors in new product development and selecting new product portfolio. The critical success factors are identified on the basis of an enterprise system, including the fields of project management, marketing and customer's comments concerning the previous products. The model of measuring the success of a product includes the indicators such as duration and cost of product development, and net profit from a product. The proposed methodology is based on identification of the relationships between product success and project environment parameters with the use of artificial neural networks and fuzzy neural system that is compared with the results from linear model. The presented method contains the stages of knowledge discovery process such as data selection, data preprocessing, and data mining in the context of an enterprise resource planning system database. The illustrative example enhances a performance comparison of intelligent systems in the context of data preprocessing.
\end{abstract}

Keywords: project management, new product development, knowledge acquisition, data mining, ERP system.

\section{Introduction}

New product development (NPD) is one of the most important processes in maintaining a company's competitive position and continuing business success. New products and innovations impact on sales volume, employment, technological process, and economic progress. Contribution of NPD to the growth of the companies, its influence on profit performance, and its role as a key factor in business planning has been widely considered [e.g. 1-3]. Nevertheless, it is still reported that the success rate of product development projects is unsatisfactory, with more cost and time than expected having been consumed to achieve the project goals.

The main reasons why most companies have failed in the development of new products derive from extrinsic and intrinsic problems. Extrinsic problems include flops in the market, changes in regulations or simply competition develops product first [4]. Intrinsic problems concern the limited resource constraints (e.g. temporal, financial, and human) and result in the difficulties to meet the project goals, including product innovativeness. Unsatisfactory success rate of product development projects can also be considered from the perspective of inherent feature of NPD, that is, it is a rela- tively risky activity [5], as market competition and product technology advancement are often intense [6].

Although the success of a new product depends on the environmental uncertainties that are beyond a firm's control, companies should take into account both external and internal indices that can impact on the product success. Internal indices can be acquired from company's databases, including Enterprise Resource Planning (ERP) system, project management software, customer relationship management system, etc.

The proper choice of critical success factors and metrics can improve the accuracy of new product evaluation, determine an optimal set of new products for development, more effectively use the company's resources, and finally reduce an unnecessary cost. A key challenge faced by new product development projects is how to acquire knowledge, sustain success rate among the products, and manage the project in order to reduce the risk of failure of the product [4].

This study aims to develop an approach that identifies the relationships between the success of a product and the key factors that are stored in an enterprise information system and that influence on this success. 


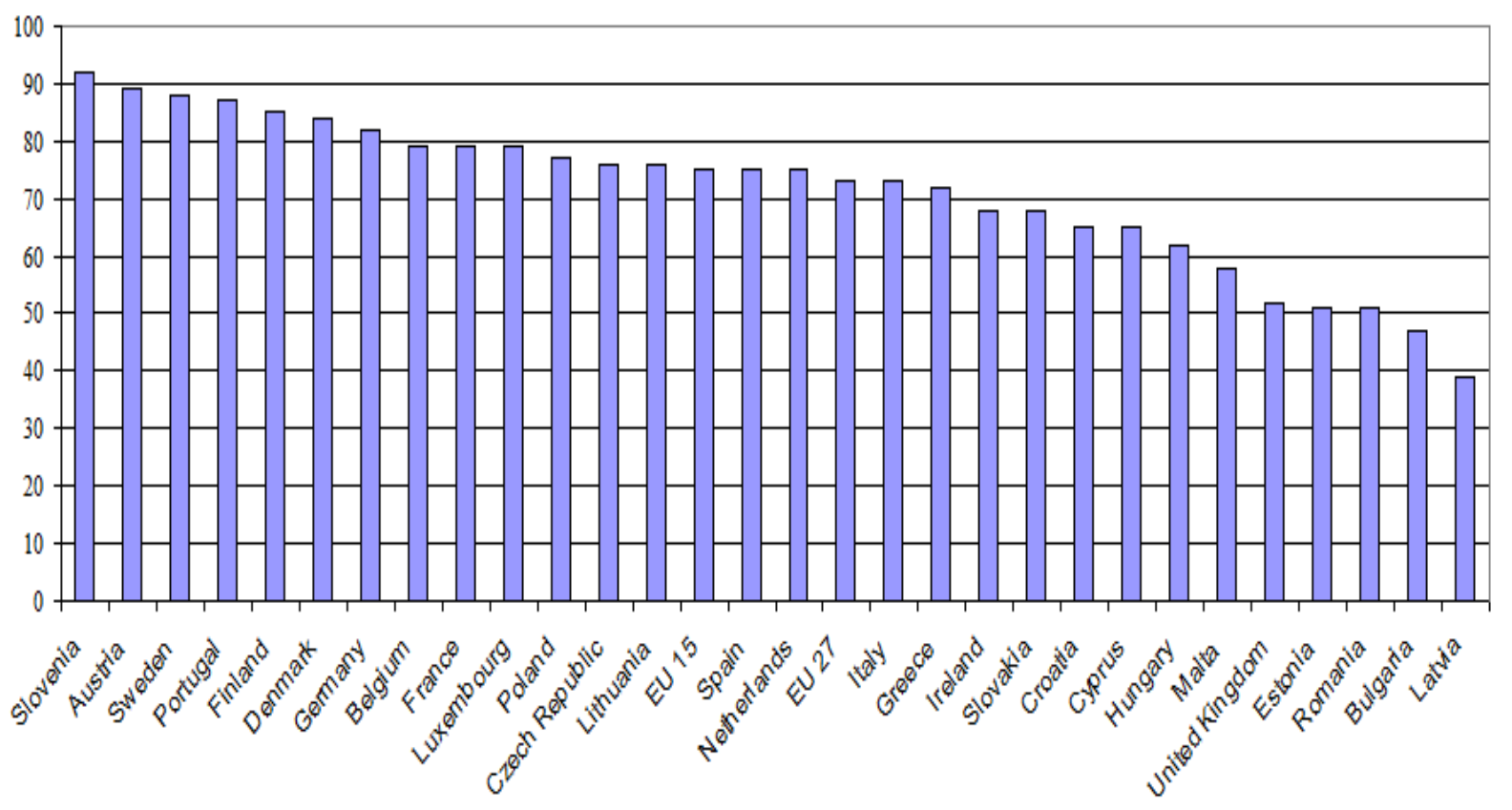

Figure 1. Use of ERP software in large enterprises in the EU countries in 2013 (in \%) (source: [10])

This approach takes into account data of the previous projects that can be retrieved from an ERP system, including the fields such as marketing and sales, production, project management and the customers' complains. The identification of patterns from an ERP database uses computational intelligence techniques, such as the artificial neural networks and fuzzy neural system. The sought relationships are used for estimating the success rate of the products that are considered for development, and proposing such changes in project environment that can increase the chance to develop a successful product. The set of potential products for development is determined with the use of integer programming taking into account the company's constraints.

The novelty of this research concerns the proposed model of measuring product success that is adjusted to the structure of an ERP system. The proposed approach has several advantages such as the low effort of data retrieval (the data are accessible in an ERP system) and creating new ideas for product development on the basis of customers' complaints, requirements, comments that are registered in an ERP system. The proposed methodology is based on computational intelligence techniques that enable pattern recognition in the large databases but also require preprocessing of data. Therefore, the aspect of data preprocessing is enhanced in this study.
The remaining sections of this paper are organized as follows: section 2 presents the literature review regarding enterprise resource planning systems and measurement of product success. A model of measuring product success with the use of an ERP database is presented in section 3 . The proposed method of product portfolio selection is shown in section 4 . An example of the proposed approach, which includes a comparison between intelligent systems and linear model for estimating the success of a product, is illustrated in section 5. Finally, some concluding remarks are contained in section 6 .

\section{Literature review}

\subsection{Enterprise resource planning systems}

In recent years, the advancement of information technology in business management processes has placed ERP system as one of the most widely implemented business software in various enterprises. ERP systems help to collect, operate, and store data connected with the daily business processes in an enterprise (e.g. customer orders, goods receipts) [7-9]. The use of an ERP system is especially widespread in the large- and medium-sized enterprises (see Fig. 1 and Fig. 2), where the enormous number of business processes appears. 


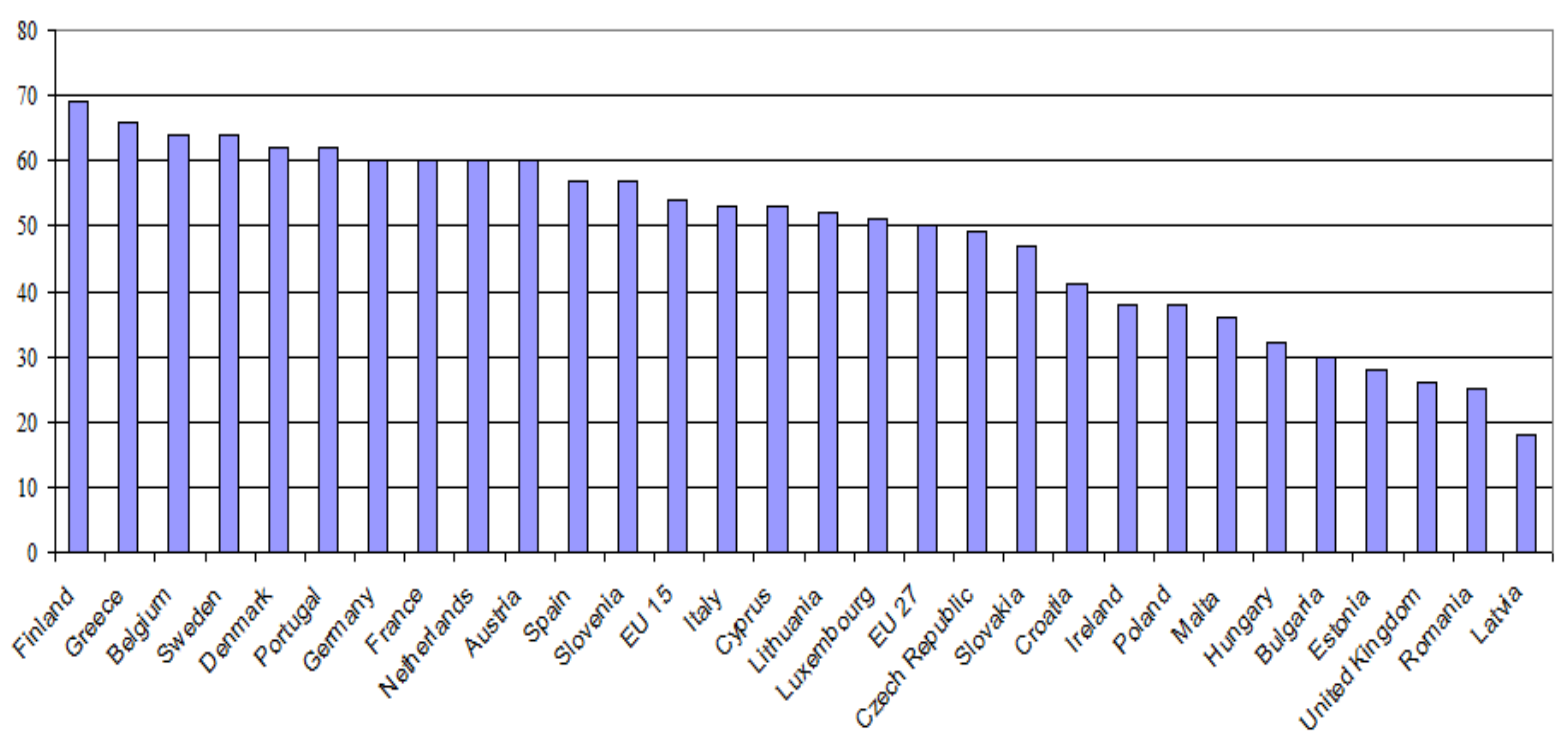

Figure 2. Use of ERP software in medium enterprises in the EU countries in 2013 (in \%)

(source: [10])

An ERP system is an integrated information technology (IT) that uses common databases and consistent crossfunctional information flow to allow companies to integrate information from different departments and locations [11]. The primary task of an integrated system is to maintain the data flow of an organization and to reduce the redundancy [12-13]. An ERP system can also be considered as the seamless integration of all the information flowing through the company such as finances, accounting, human resources, supply chain, and customer information [14]. Main objectives for an ERP system implementation are connected with maximization of business process effectiveness, data analysis, system use, organizational IT competence, productive working relationships, information richness and security, as well as minimization of information dispersion. These objectives aim to minimize cost and maximize customer relationship effectiveness, and product and services improvement [13].

New product development process can be supported by project management software in the form of an alone IT tool (e.g. Microsoft Project) [15-16] or an integrated approach such as an ERP system [8-9]. In the case of new products that are only small-scale modifications, there is possibility to use the past project parameters and other ERP attributes (e.g. marketing cost, production cost, customer complaints) in order to seek the relationships among the data. These relationships aim at improving estimation quality for duration and cost of new product development, and the success of a product.

\subsection{Measurement of product success}

The definition of a successful project is in the various ways considered in the literature [e.g. 17-19]. As measuring criteria, the fulfillment of a fixed goal, the compliance with budget progress, or achieving an acceptable level of performance were used in past studies. Pinto and Mantel identified three aspects of project performance as benchmarks for measuring the success or failure of a project: the implementation process, the perceived value of the project, and client satisfaction with the final product [20]. Freeman and Beale identified seven main criteria to measure projects success: technical performance, efficiency of execution, managerial and organizational implications (mainly customer satisfaction), personal growth and a manufacturer's ability, business performance, project termination, and technical innovativeness [21]. Cooper and Kleinschmidt presented the multidimensional nature of NPD performance with 10 measures [22]: success rate, percent of sales, profitability relative to spending, technical success rating, sales impact, profit impact, success in meeting sales objectives, success in meeting profit objectives, profitability relative to competitors, and overall success.

Lipovetsky et al. defined four dimensions for measuring the success of various projects [23]: meeting design goals, benefits to the customer, benefits to the developing organization, and benefits to the defense and national infrastructure. 
Table 1. The criteria for measuring product success (source: [19-25])

\begin{tabular}{|c|c|}
\hline Authors & Criteria \\
\hline $\begin{array}{l}\text { Pinto and Mantel } \\
\text { (1990) }\end{array}$ & $\begin{array}{l}\text { The implementation process } \\
\text { The perceived value of the project } \\
\text { Client satisfaction with the final product }\end{array}$ \\
\hline $\begin{array}{l}\text { Freeman and Beale } \\
\qquad(1992)\end{array}$ & $\begin{array}{l}\text { Technical performance } \\
\text { Efficiency of execution } \\
\text { Managerial and organizational implications } \\
\text { Personal growth and a manufacturer's ability } \\
\text { Business performance } \\
\text { Project termination } \\
\text { Technical innovativeness }\end{array}$ \\
\hline $\begin{array}{l}\text { Cooper and Kleinschmidt } \\
\qquad(1995)\end{array}$ & $\begin{array}{l}\text { Success rate } \\
\text { Percent of sales } \\
\text { Profitability relative to spending } \\
\text { Technical success rating } \\
\text { Sales impact } \\
\text { Profit impact } \\
\text { Success in meeting sales objectives, success in meeting } \\
\text { profit objectives, profitability relative to competitors, } \\
\text { overall success }\end{array}$ \\
\hline $\begin{array}{l}\text { Lipovetsky et al. } \\
\text { (1997) }\end{array}$ & $\begin{array}{l}\text { Meeting design goals } \\
\text { Benefits to the customer } \\
\text { Benefits to the developing organization } \\
\text { Benefits to the defense and national infrastructure }\end{array}$ \\
\hline $\begin{array}{l}\text { Sounder and Song } \\
\text { (1997) }\end{array}$ & $\begin{array}{l}\text { Sales } \\
\text { Market share } \\
\text { Return on investment } \\
\text { Profit } \\
\text { Customer satisfaction } \\
\text { Contribution to technology leadership } \\
\text { Contribution to market leadership }\end{array}$ \\
\hline $\begin{array}{l}\text { Sun and Wing } \\
\qquad(2005)\end{array}$ & $\begin{array}{l}\text { Clearly defined target market } \\
\text { Implementation of quality standards, clear project goal, consider } \\
\text { issues at early stage } \\
\text { Internal communication within the project team } \\
\text { Delivery of new product to customers on time, right time } \\
\text { to launch, competitive product cost }\end{array}$ \\
\hline
\end{tabular}


Table 1 (cont.). The criteria for measuring product success (source: [19-25])

\begin{tabular}{|l|l|}
\hline \multirow{2}{*}{ Wei et al. } & $\begin{array}{l}\text { Proficiency of pre-development } \\
\text { Proficiency of the whole process } \\
\text { Proficiency of scheme } \\
\text { Proficiency of development } \\
\end{array}$ \\
& Proficiency of market launch \\
\hline
\end{tabular}

Sounder and Song proposed seven criteria in making overall judgments about the new product development in the context of actual performance versus the original expectations [24]: sales, market share, return on investment, profit, customer satisfaction, contribution to technology leadership, and contribution to market leadership. Sun and Wing identified the product success with clearly defined target market, project goal, internal communication, right time to launch, and competitive product cost [19]. In turn, Wei et al. considered the new product development (NPD) project success as the proficiency of pre-development, scheme (the welldefined new product performance and NPD project target), whole process, development, and market launch [25]. Table 1 presents the different approaches for evaluating the success of a project.

New product development is a complicated and timeconsuming process in which several different activities are involved. Sun and Wing presented the NPD process in the context of the following phases: ideas generation and conceptual design, definition and specification, prototype and development, and commercialization [19]. In turn, Cooper and Kleinschmidt presented four main aspects of NPD process which bring positive influences for NPD project success [22]: the clear definition of product before development begins (including product concept and target market), the high quality preparatory work (including the detailed technical and market-oriented feasibility studies, and a commercial evaluation of the NPD project), the clear orientation of NPD process to market (including market research activity and competition observation), and the existence of a high quality NPD process control. All these aspects are critical for the NPD project success; however, the focus on the early phases of NPD project can reduce the cost in the further phases.

Literature review on the product success metrics summarized in Table 1 shows that most of the proposed approaches are based on the evaluation of multiple criteria. From the company perspective, it is especially important to determine such critical success factors that can be retrieved from an internal database and that enable the decision to terminate the unpromising projects before the beginning of the NPD process. In this study, measuring the success of a product is based on quantitative criteria concerning marketing, production and project performance for which data is stored in an ERP system. The issue of the data retrieval from an enterprise system to evaluate a NPD process is neglected in the above approaches. This is the motivation to develop a model of measuring the success of a product that is based on an ERP database.

\section{Model of measuring product success on the basis of an ERP database}

The enterprise systems generate routinely an enormous amount of data according to the business processes in a company. As the amount of available data in companies becomes greater and greater, companies have become aware of an opportunity to derive valuable information from their databases, which can then be used to improve their business [26]. The process of identifying valid, novel, potentially useful, and ultimately understandable patterns in data is known as knowledge discovery [27]. The knowledge discovery process includes the stages such as data selection, data preprocessing, data transformation, data mining, and interpretation (evaluation) of the patterns identified $[9,27]$.

Analysis of the data and knowledge acquisition with the use of manual methods is slow, expensive, subjective, and prone to errors. Hence, there is a need to automate the process through using data mining techniques. The most commonly used tasks in data mining include classification, clustering, associations, visualization, summarization, deviation detection, link analysis, and estimation that is further considered. 


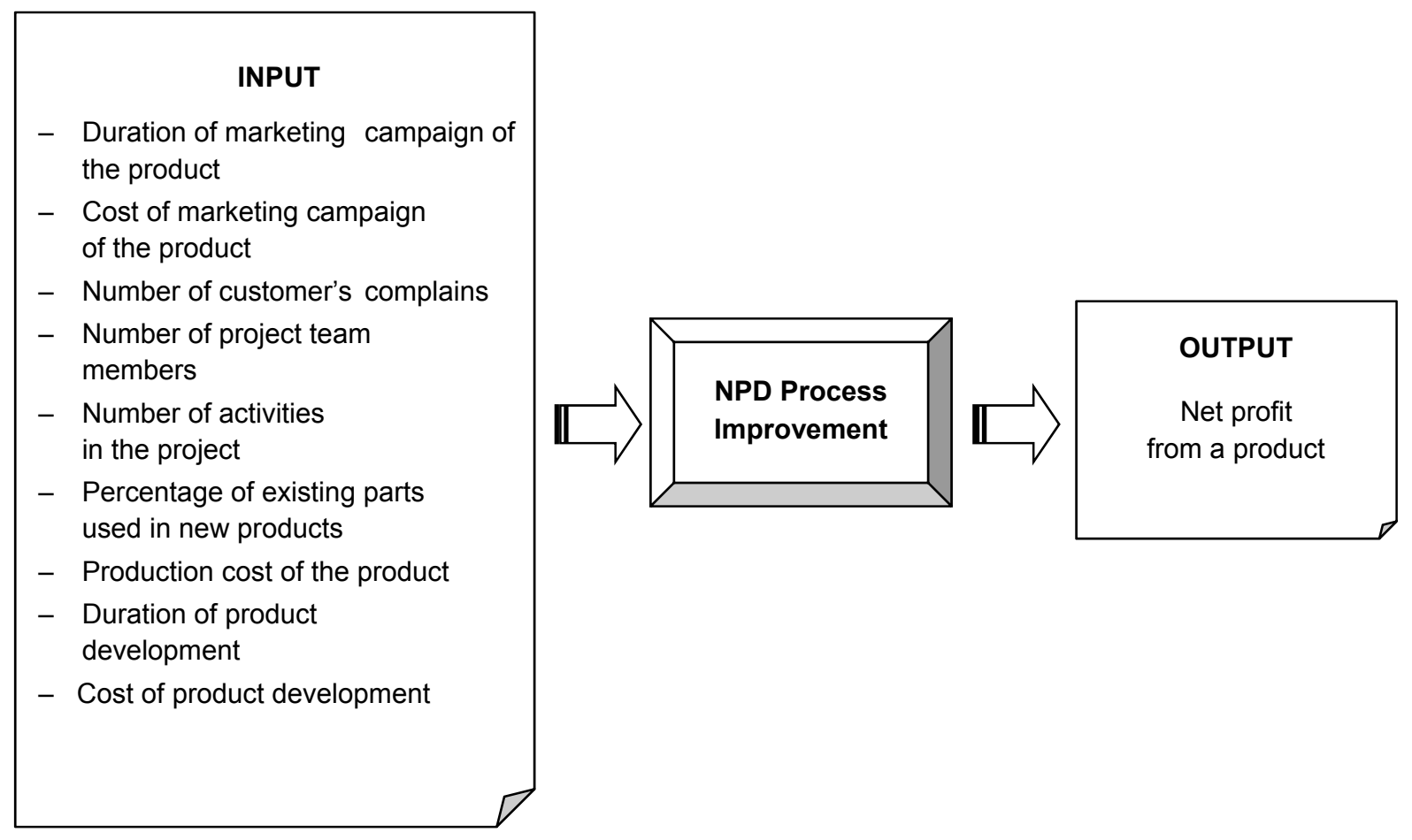

Figure 3. Input-output system of NPD process improvement (source: own elaboration)

The proposed model consists of variable that describes the product's success (output data) and variables that are suspected of having a significant impact on this success (input data). The model has been elaborated on the basis of the previous studies that included observation of successful companies and confrontation with literature (see Table 1), as well as from the perspective of data stored in an enterprise system (e.g. ERP and $\mathrm{CRM}^{1}$ system, project management software).

The success of a product can be measured in profit growth, export rate, success rate of new products, market share, etc. Taking into account the product lifetime and return on product development expense, as the output variable and the measure of the product success, the average net profit from a product per month is chosen. In turn, the input variables are classified into the fields such as marketing, customer, project management, and finance. Performance indicators (input variables) for marketing perspective include duration of marketing campaign of the product and cost of marketing campaign of the product; for customer perspective - number of customer's complains (requirements, comments) for the previous products that have been used to developing a new product; for project management perspective - number of employees who directly develop a new product (project team members), number of activities in the project, percentage of existing parts used in new products; for finance perspective production cost of the product. These variables can be retrieved from an enterprise system database. Figure 3 presents input-output system for measuring the success of a product, and consequently, for improving the NPD process.

The presented model is based on the assumptions such as access to data of past successful and unsuccessful NPD projects, including their cost, duration, team members, and current market position of a product. The model enables the identification of relationships between the success of new product and the key factors in the field of project management that influence on this success, and it can be considered in terms of learning from the past experiences to improve the success of products in the development process.

\footnotetext{
1 Customer Relationship Management, denoting strategies and software that enable a company to organize and optimize its customer relations.
} 


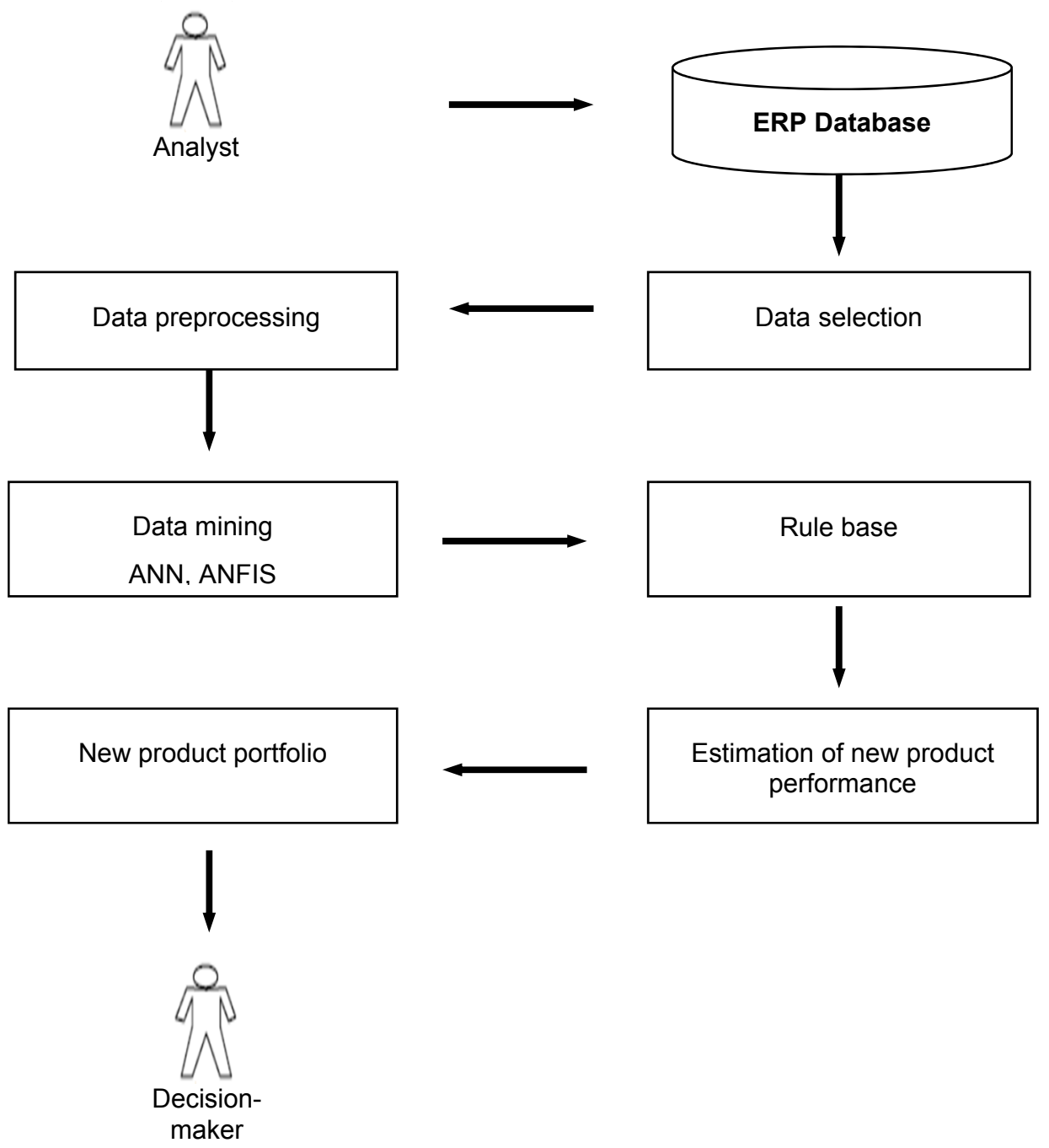

Figure 4. Framework of product portfolio selection (source: own elaboration)

The solution of the considered problem includes seeking answers to the following questions: is there a significant relationship between the marketing and project management parameters and the success of a product? Are accessible resources in company to improve the effectiveness of project management, and finally, the success rate? What parameters should have the current projects to increase their chances for the success? What is a set of input variables that impacts the strongest on the output variable?

The sought relationships can indicate the directions of improvement of products that are in the development process and, as a result, increase the chance to develop a successful product and support the success rate from new products in a company. The pattern identification from an ERP database requires using the specific knowledge discovery methods that are adjusted to the characteristics of an ERP system. A method for seeking the relationships among ERP parameters, selecting new product portfolio, and obtaining the answers to the above questions is presented in the next section.

\section{$4 \quad$ Method for product portfolio identification}

The method consists of the following phases: data selection from an ERP database by analysts, data preprocessing, data mining and identification of patterns (rule base) with the use of the artificial neural networks (ANN) and the adaptive neuro-fuzzy inference system (ANFIS), and selection of the most promising new products to the project portfolio. Figure 4 illustrates the phases of the proposed method. 
The use of ANN and ANFIS requires preprocessing the data that is retrieved from ERP systems [28-30]. One of the feature reduction methods is principal component analysis (PCA) that reduces the dimension for linearly mapping high dimensional data onto a lower dimension with minimal loss of information. Data preprocessing has been performed with the use of PCA that is the best, in the mean-square error sense, linear dimension reduction technique [31]. In the next step, the relationships among the chosen variables are sought with the use of ANN and fuzzy neural system.

Pattern discovery from databases requires some data mining techniques that cope with the description of relationships among data and that solve the problems connected with, for example, classification, regression, and clustering. These techniques include neural networks, fuzzy sets, rough sets, time series analysis, Bayesian networks, decision trees, evolutionary programming and genetic algorithms, etc. The ANN and fuzzy logic are complementary technologies and powerful design techniques that can be used in the identification of patterns from within a large database and noisy data that is common for an ERP system.

ANN are an important class of tools for quantitative modeling. Nowadays, ANN are treated as a standard data mining tool and used for many data mining tasks such as pattern classification, time series analysis, prediction, and clustering. Neural networks are computing models for information processing and are particularly useful for identifying the fundamental relationship among a set of variables or patterns in the data. The popularity of neural networks is due to their powerful modeling capability for pattern recognition. Among characteristics of ANN that make them suitable and valuable for data mining are the lack of several unrealistic a priori assumptions about the underlying data generating process and specific model structures, nonlinearity of ANN models, ability of solving problems that have imprecise patterns or data containing incomplete and noisy information with a large number of variables. This fault tolerance feature is appealing for data mining problems because real data is usually noisy and does not follow clear probability structures, which are typically required by statistical models [32].

The fuzzy neural system has the advantages of both neural networks (e.g. learning abilities, optimization abilities and connectionist structures) and fuzzy systems (simplicity of incorporating expert knowledge).
As a result, it is possible to bring the low-level learning and computational power of neural networks into fuzzy systems and also high-level human like IF-THEN thinking and reasoning of fuzzy systems into neural networks. The behavior of a fuzzy neural system can be represented by a set of humanly understandable rules or by a combination of localized basis functions associated with local models, making them an ideal framework to perform nonlinear predictive modeling [33]. One well-known structure is the ANFIS that enables the nonlinear modeling, simulation, and forecasting.

The success of a product is estimated with the use of the relationships identified (rule base) and further used to select the most promising products for development. This product portfolio takes into account the constraints (financial, temporal, personal, etc.) and can be determined with the use of the constraint programming [34-39]. In the process of choosing the optimal product portfolio, the decision maker can be involved through the weights preferred for the criteria considered. The next section presents an example of the use of the proposed approach to identify net profit value for products and select the optimal product portfolio for development.

\section{$5 \quad$ Illustrative example}

The illustrative example consists of three parts that refer to the presented methodology:

- description of the variables used to carry out the analysis,

- identification of the relationships between input variables and the success of a product,

- determination of the optimal product portfolio for the development process.

\subsection{Description of the variables used in the example}

The output variable is net profit from a product that is treated as a measure of product success. The input variables concern the fields of marketing, project management, research and development (R\&D), and production that can be retrieved from an enterprise's internal database, for instance, an ERP system. 
Table 2. Planned values of input variables for new product projects (source: own elaboration)

\begin{tabular}{|c|c|c|c|c|}
\hline Input variable & P1 & P2 & P3 & P4 \\
\hline I1 & 26 & 19 & 33 & 37 \\
\hline I2 & 86 & 68 & 102 & 115 \\
\hline I3 & 25 & 13 & 29 & 32 \\
\hline I4 & 9 & 4 & 7 & 12 \\
\hline I5 & 60 & 35 & 71 & 84 \\
\hline I6 & 0.45 & 0.67 & 0.34 & 0.25 \\
\hline I7 & 0.14 & 0.21 & 0.39 & 0.59 \\
\hline I8 & 26 & 15 & 29 & 36 \\
\hline I9 & 54 & 27 & 69 & 78 \\
\hline
\end{tabular}

Taking into account the literature review of measuring product success, the following input variables have been chosen:

- period of marketing campaign of the product (I1),

- cost of marketing campaign of the product (I2),

- number of customer's complaints for the previous products that have been used to develop a new product (I3),

- number of employees who directly develop a new product (I4),

- number of activities in the NPD project (I5),

- percentage of existing parts used in a new product (I6),

- unit cost of production for the product (I7),

- period of product development (I8),

cost of product development (I9).The success of new product is estimated on the basis of the parameters of the previous NPD projects. There are sought the relationships between the above-described input variables and net profit from a product. Moreover, some input variables can be used to estimate the period of product development $\{\mathrm{I} 3, \mathrm{I} 4, \mathrm{I} 5, \mathrm{I} 6\}$, and the cost of product development $\{\mathrm{I} 3, \mathrm{I} 4, \mathrm{I} 5, \mathrm{I} 6, \mathrm{I} 8\}$. Let us assume that the initial project portfolio includes the development of four products $\{\mathrm{P} 1, \mathrm{P} 2, \mathrm{P} 3, \mathrm{P} 4\}$. The project resources such as employees in R\&D department and project portfolio budget are limited to 21 people and 148 monetary units. Table 2 presents the planned values of input variables for new products that are considered for the development process.

\subsection{Identification of relationships}

The identification of relationships between the input variables and net profit from a product has been sought with the use of intelligent systems such as the ANFIS and ANN. In order to eliminate the overtraining of ANFIS and ANN (too strict function adjustment to data) and to increase the estimation quality, the data set has been divided into learning (P1-P25) and testing sets (P26-P32).

The results have been calculated in the Matlab ${ }^{\circledR}$ software and presented in Table 3 as the root mean square errors (RMSE) for the learning and testing set. The results for ANFIS and ANN are compared with the average and linear model that is determined according to the ordinary least squares method.

In studies, a multilayer feed-forward neural network was trained according to the back-propagation algorithm. Weights were optimized according to the Levenberg-Marquardt algorithm (LM) and gradient descent momentum with adaptive learning rate algorithm (GDX). The neural network structure was determined in an experimental way, by the comparison of learning and testing sets for the different number of layers and hidden neurons.

The RMSE was calculated as the average of 20 iterations for each structure of neural network with a number to the extent of 20 hidden neurons. 
Table 3. Comparison of RMSE for different models (source: own elaboration)

\begin{tabular}{|l|c|c|c|c|}
\hline \multirow{2}{*}{ Model } & \multicolumn{2}{|c|}{ Without preprocessing } & \multicolumn{2}{c|}{ With preprocessing } \\
\cline { 2 - 5 } & Learning set & Testing set & Learning set & Testing set \\
\hline ANN - GDX & 70.22 & 67.77 & 26.40 & 24.22 \\
\hline ANN - LM & 45.79 & 43.41 & $9 \mathrm{e}-12$ & 33.84 \\
\hline ANFIS - hybrid & 32.41 & 29.14 & 0.0004 & 27.14 \\
\hline ANFIS - backprop (100 iterations) & 35.89 & 27.46 & 0.407 & 26.98 \\
\hline ANFIS - backprop (1000 iterations) & 35.14 & 27.20 & 0.396 & 26.85 \\
\hline Linear model & 21.16 & 30.91 & 21.16 & 30.91 \\
\hline Average & 70.22 & 67.31 & 70.22 & 67.31 \\
\hline
\end{tabular}

In turn, ANFIS was trained according to subtractive clustering method by the use of the back-propagation and hybrid algorithm. After learning phase, the testing data was led to input of the fuzzy neural system to compare the RMSE for ANFIS and other models.

Table 3 presents the RMSE in the learning and testing set for the different models in the aspect of data preprocessing to illustrate the influence of this phase on pattern identification with the use of intelligent systems.

The results presented in Table 3 indicate that after preprocessing the least error in the testing set has been generated with the use of the neural network trained according to the gradient descent momentum with adaptive learning rate algorithm.

The ANFIS obtained better results for the learning set but a little worse results for the testing set than the neural network (GDX). In turn, the ANN trained according to the LM algorithm generated worse results than the ANFIS and the neural network (GDX). This can result from the overtraining of the neural network in the learning phase and the lack of its ability to generalization. The results presented in Table 3 indicate that the intelligent systems are able to generate better results after data preprocessing. This demonstrates the importance of the proper choice of a learning algorithm for ANN and ANFIS, preprocessing the data, and the need of result comparison for different intelligent systems that have ambiguous learning procedures. It is noteworthy that RMSE generated with the use of intelligent systems are smaller than RMSE for the average. The comparison of different forecasting models is especially recommended in the case of significant variance of an output variable.

\subsection{Determination of the optimal product portfolio}

The relationships between input and output data are stored in the structure of ANN and ANFIS. The fuzzy neural system identified 10 rules that have been used to compute the estimation of net profit for four products $\{\mathrm{P} 1, \mathrm{P} 2, \mathrm{P} 3, \mathrm{P} 4\}$. The values of input variables presented in Table 2 were led to the trained ANFIS structure in order to calculate the forecasts of net profit for the considered products.

Figures 5-8 illustrate the membership functions for the rules that are used for estimating of output variable. Net profit for products P1, P2, P3, and P4 equals 165, $96.8,192$, and 240 monetary units, respectively. 


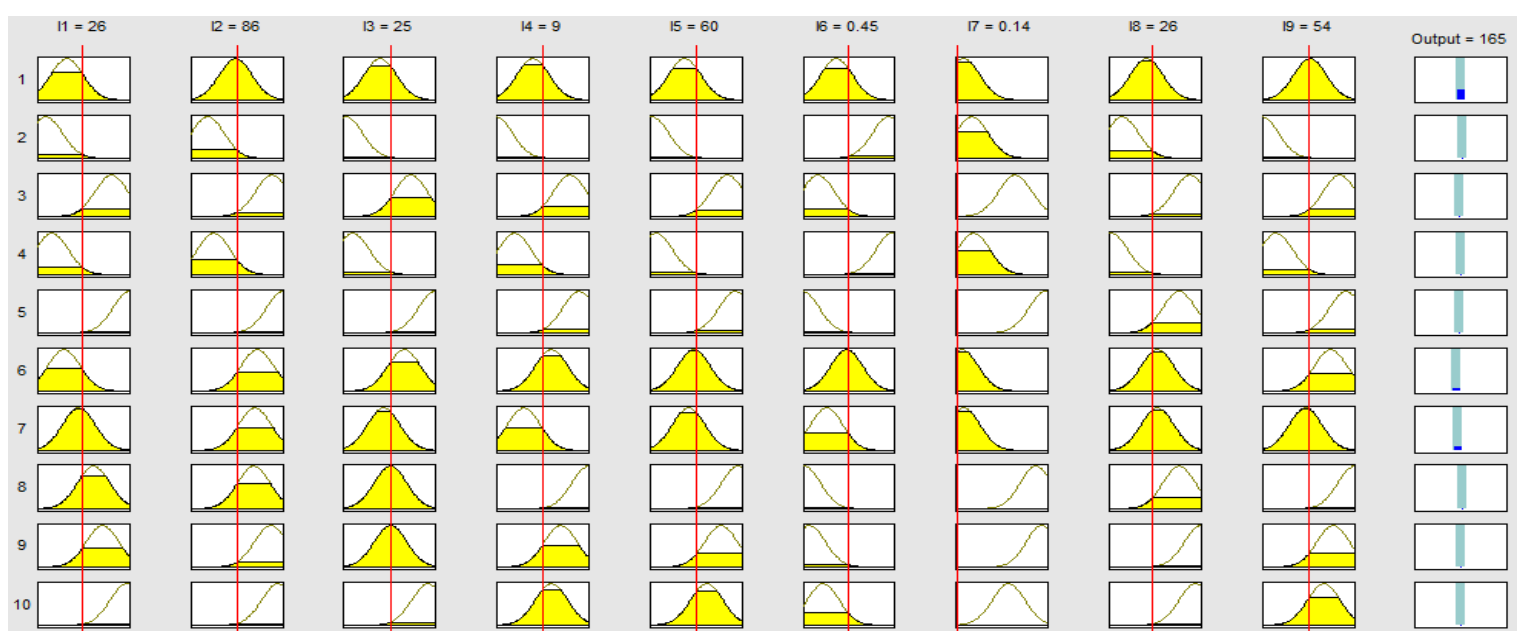

Figure 5. Estimating output variable for product P1 (source: own elaboration)

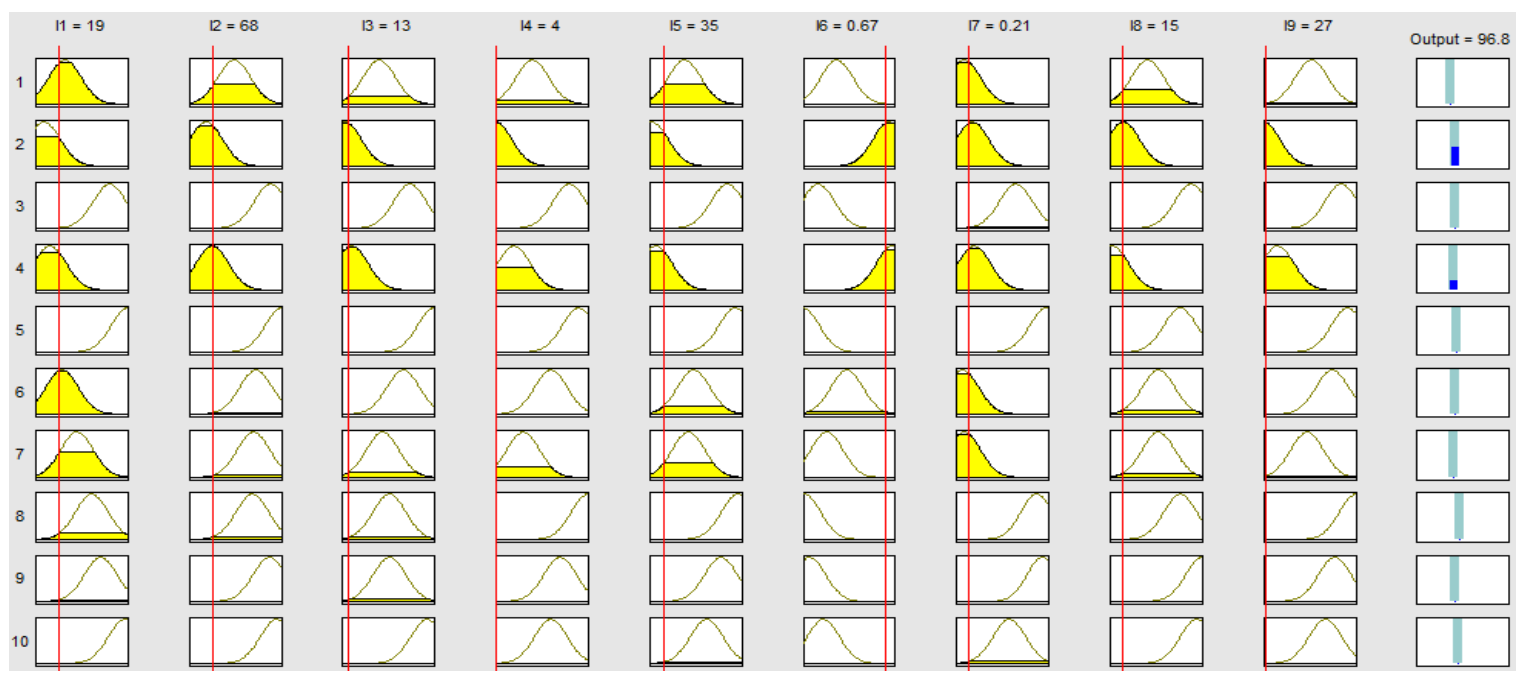

Figure 6. Estimating output variable for product P2 (source: own elaboration)

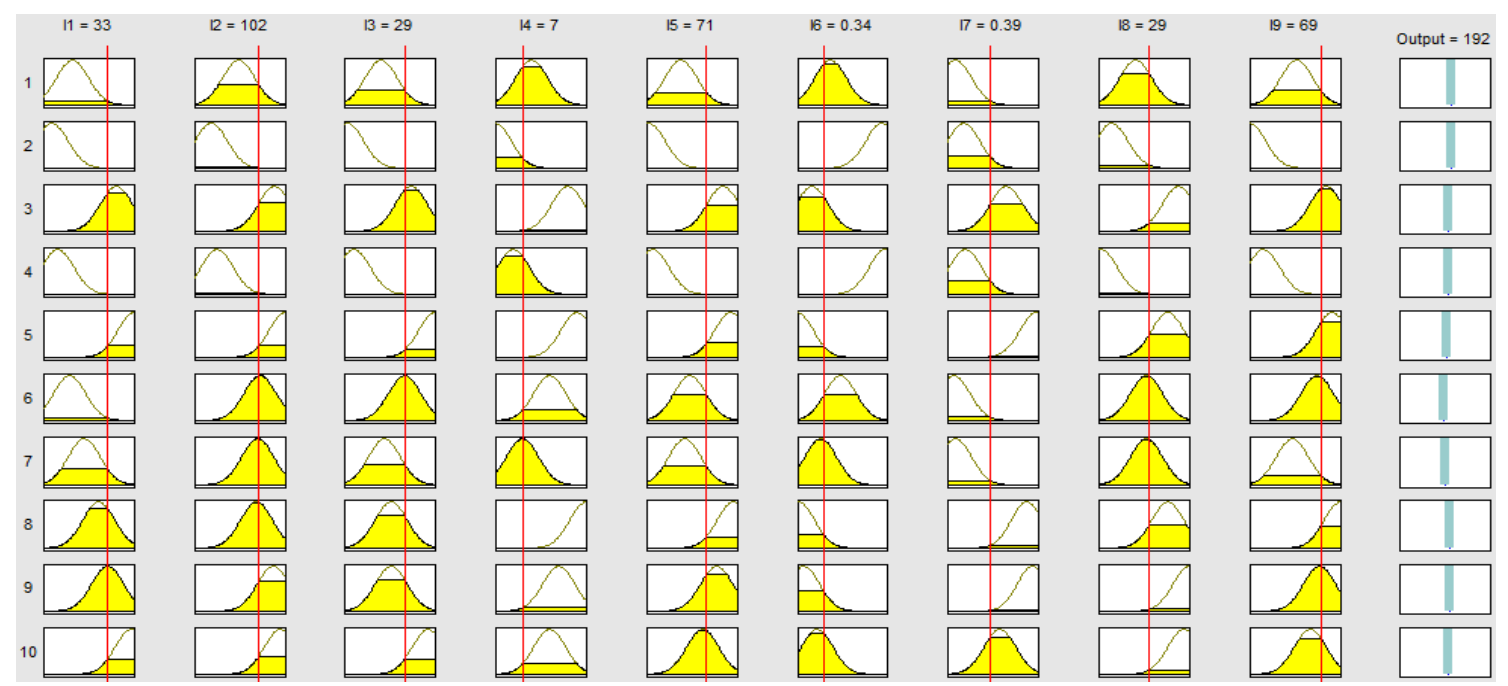

Figure 7. Estimating output variable for product $\mathrm{P} 3$

(source: own elaboration) 


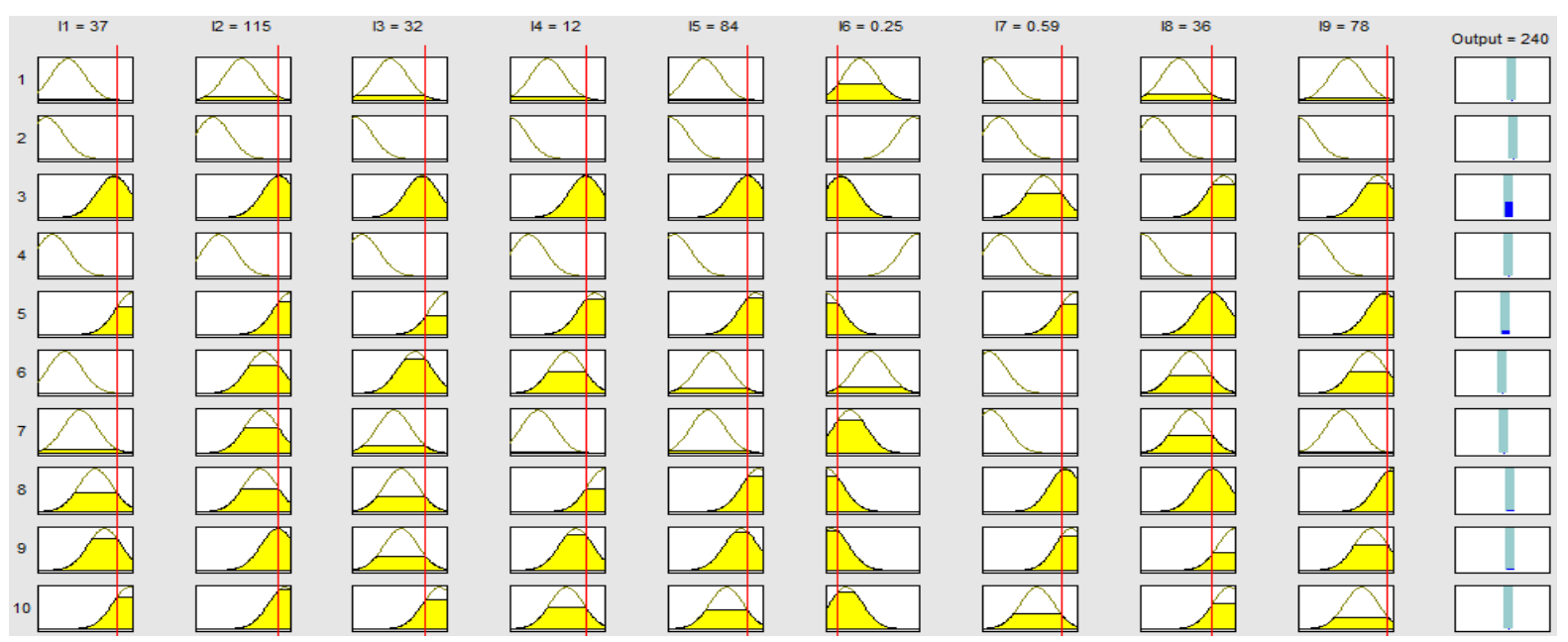

Figure 8. Estimating output variable for product $\mathrm{P} 4$ (source: own elaboration)

The assumed constraints ( $21 \mathrm{R} \& \mathrm{D}$ employees for variable I4 and 148 monetary units for variable I9) limit the number of products to a maximum of 3 out of 4 . As the criterion of project selection, the planned net profit from new product has been chosen.

From this point of view, the optimal product portfolio includes product $\mathrm{P} 3$ and $\mathrm{P} 4$. The presented analysis can be further extended towards the sensitivity analysis, what-if analysis or to obtain an answer to the question what values should have the input variables to reach the desired value of net profit from new product. This question can be considered in the context of the reverse approach [41, 42]. In order to obtain an optimal set of admissible variants, integer programming can be used. In the case of extensive search space, the processing time of calculations can be significantly reduced with the use of constraints programming techniques [34-40].

\section{Conclusions}

The continuous development and launching of new products is an important determinant of sustained company performance. However, because of its inherent features, new product development is a relatively risky activity. Failed product development projects can decrease market share, profitability, and finally, lead to bankruptcy of a company.

The rapid-evolving technology, the fast-changing markets and the more demanding customers, require developing high quality new products more efficiently and effectively. To ensure these requirements, the identification of the key success factors of product is need- ed. As an ERP system stores the data connected with the various areas of business, including customers' demand and NPD projects, its database can be used to seek the relationships between these areas and the success of a product.

This paper presents the possibility of the use of an enterprise system database for the identification of relationships between the success of a product and the factors in the field of marketing, customer complaints, production, and project management. The relationships in an ERP database are sought with the use of artificial neural networks and fuzzy neural system that has been compared with the results from linear model. The identified relationships are applied for evaluating the success rate for the products that are considered for the development process and selecting the most promising set of products. Moreover, the influence of data preprocessing on pattern identification has been verified in this study.

The proposed approach has several advantages such as the low effort of data retrieval (the data are accessible in an EPR system that is used by more and more enterprises) and creating new ideas for developing products on the basis of customers' complaints, requirements, and comments that are registered through customer relationship management system.

Moreover, the recognized patterns can be the basis of a decision support system that helps the managers in selecting the most promising product portfolio and reducing the risk of unsuccessful product development. 
The proposed approach gives new insights into the literature of pattern identification with the use of an enterprise system database that aims to improve development of new products, and finally, the success rate of products. On the other hand, the application of the proposed approach encounters some difficulties, for instance, collecting enough amounts of data from the past similar NPD projects and ambiguous rules for creating the artificial neural network structure and fuzzy neural system.

Nevertheless, the presented approach seems to have the promising properties for acquiring information from an ERP system and improvement of the decisionmaking process in the context of selecting new product portfolio.

\section{$7 \quad$ References}

[1] Benedetto C.A. - Identifying the key success factors in new product launch [in] Journal of Product Innovation Management, Vol. 16, 1999, pp. 530-544.

[2] Cooper R., Edgett S. - Maximizing productivity in product innovation [in] Research Technology Management, Vol. 51, No. 2, 2008, pp. 47-58.

[3] Ulrich K.T., Eppinger S.D. - Product design and development. McGraw-Hill 2011.

[4] Cooper L.P. - A research agenda to reduce risk in new product development through knowledge management: a practitioner perspective [in] Journal of Engineering and Technology Management, Vol. 20, No. 1, 2003, pp. 117-140.

[5] Kahraman C., Buyukozkan G., Ates N.Y. - A two phase multi-attribute decision-making approach for new product introduction [in] Information Sciences, Vol. 177, No. 7, 2007, pp. 1567-1582.

[6] McCarthy I.P., Tsinopoulos C., Allen P., RoseAnderssen C. - New product development as a complex adaptive system of decisions [in] Journal of Product Innovation Management, Vol. 23, No. 5, 2006, pp. 437-456.

[7] Sikora M., Borowski Z., Majchrzak M. - Zintegrowane systemy informatyczne $w$ organizacji gospodarki magazynowej [in] Logistyka, Vol. 2, 2012, pp. 1005-1014.

[8] Relich M. - Knowledge acquisition for new product development with the use of an ERP database [at] Proceedings of the Federated Conference on Computer Science and Information Systems, Kraków 2013, pp. 1285-1290.
[9] Relich M. - Project parameter estimation on the basis of an ERP database [in] Foundations of Management - International Journal, Vol. 5, No. 2, 2013, pp. 49-58.

[10] Eurostat, data code: isoc_bde15dip, http://epp.eurostat.ec.europa.eu/portal/page/portal/s tatistics/search_database (accessed on 2014.10.03)

[11] Tsai W.H., Lee P.L., Shen Y.S., Lin H.L. - A comprehensive study of the relationship between enterprise resource planning selection criteria and enterprise resource planning system success [in] Information \& Management, Vol. 49, 2012, pp. 3646.

[12] Imtiaz A., Kibria M.G. - Modules to optimize the performance of an ERP based integrated information system [at] IEEE International Conference on Informatics, Electronics \& Vision, 2012, pp. 598-601.

[13] May J., Dhillon G., Caldeira M. - Defining valuebased objectives for ERP systems planning [in] Decision Support Systems, Vol. 55, 2013, pp. 98109.

[14] Davenport T. - Putting the enterprise into the enterprise system [in] Harvard Business Review, July-August 1998, pp. 121-131.

[15] Doskočil R. - Microsoft Project as a knowledge base for project management [at] 22nd International Business Information Management Association Conference on Creating Global Competitive Economies. Rome 2013, pp. 1412-1418.

[16] Doskočil R., Smolíková L. - Knowledge management as a support of project management [in] Knowledge for Market Use 2012. Societas Scientiarum Olomucensis II, Olomouc 2012, pp. 40-48.

[17] Chang P.L., Chen K.L. - The influence of input factors on new leading product development projects in Taiwan [in] International Journal of Project Management, Vol. 22, 2004, pp. 415-423.

[18] Ernst H. - Success factors of new product development: a review of the empirical literature [in] International Journal of Management Reviews, Vol. 4, No. 1, 2002, pp.1-40.

[19] Sun H., Wing W. - Critical success factors for new product development in the Hong Kong toy industry [in] Technovation, Vol. 25, 2005, pp. 293-303.

[20] Pinto J.K., Mantel S.J. - The causes of project failure [in] IEEE Engineering Management, Vol. 37, No. 4, 1990, pp. 269-276.

[21] Freman M., Beale P. - Measuring project success [in] Project Management Journal, Vol. 23, No. 1, 1992, pp. 8-17. 
[22] Cooper R.G., Kleinschmidt E.J. - Benchmarking the firm's critical success factors in new product development [in] Journal of Product Innovation Management, Vol. 12, 1995, pp. 374-391.

[23] Lipovetsky S., Tishler A., Dvir D. - The relative importance of project success dimensions [in] R\&D Management, Vol. 27, No. 2, 1997, pp. 97106.

[24] Souder W.E., Song X.M. - Contingent product design and marketing strategies influencing new product success and failure in US and Japanese electronic firms [in] Journal of Product Innovation Management, Vol. 14, 1997, pp. 12-21.

[25] Wei F., Jun C., Lixiong O. - Factor analysis on CSFs of enterprise new product development projects: based on NPD process [at] 4th International Conference on Wireless Communications, Networking and Mobile Computing, 2008, pp. 1-6.

[26] Li T., Ruan D. - An extended process model of knowledge discovery in database [in] Journal of Enterprise Information Management, Vol. 20, No. 2, 2007, pp. 169-177.

[27] Fayyad U., Piatetsky-Shapiro G., Smith P. - From data mining to knowledge discovery in databases. American Association for Artificial Intelligence, Fall 1996, pp. 37-54.

[28] Relich M. - A decision support system for alternative project choice based on fuzzy neural networks [in] Management and Production Engineering Review, Vol. 1, No. 4, 2010, pp. 46-54.

[29] Relich M. - An evaluation of project completion with application of fuzzy set theory [in] Management, Vol. 16, No. 1, 2012, pp. 216-229.

[30] Relich M., Muszyński W. - The use of intelligent systems for planning and scheduling of product development projects [in] Procedia Computer Science, Vol. 35, 2014, pp. 1586-1595.

[31] Chizi B., Maimon O. - Dimension reduction and feature selection [in] Data mining and knowledge discovery handbook. Springer 2010, 2nd ed.

[32] Zhang G.P. - Neural networks for data mining [in] Data mining and knowledge discovery handbook. Springer 2010, 2nd ed.
[33] Azar A.T. - Adaptive neuro-fuzzy systems [in] Fuzzy systems (ed. A.T. Azar). In-Tech, Vienna, Austria 2010.

[34] Banaszak Z., Zaremba M., Muszyński W. - Constraint programming for project-driven manufacturing [in] International Journal of Production Economics, Vol. 120, 2009, pp. 463-475.

[35] Bocewicz G., Banaszak Z. - Declarative approach to cyclic steady state space refinement: periodic process scheduling [in] The International Journal of Advanced Manufacturing Technology, Springer 2013, Vol. 67, Issue 1-4, pp. 137-155.

[36] Relich M., Jakabova M. - A decision support tool for project portfolio management with imprecise data [at] 10th International Conference on Strategic Management and its Support by Information Systems, 2013, pp. 164-172.

[37] Relich M. - Fuzzy project scheduling using constraint programming [in] Applied Computer Science, Vol. 9, No. 1, 2013, pp. 3-16.

[38] Relich M. - A constraint programming approach for scheduling in a multi-project environment [in] International Journal of Advanced Computer Science and Information Technology, Vol. 3, No. 2, 2014, pp. 156-171.

[39] Sitek P., Wikarek J. - Cost optimization of supply chain with multimodal transport [at] Proceedings of the Federated Conference on Computer Science and Information Systems, 2012, pp. 1111-1118.

[40] Sitek P., Wikarek J. - A hybrid approach to modeling and optimization for supply chain management with multimodal transport [at] 18th International Conference on Methods and Models in Automation and Robotics, 2013, pp. 777-782.

[41] Relich M. - Liquidity management in a small enterprise by the application of reverse approach [in] Management, Vol. 10, No. 2, 2006, pp. 129-137.

[42] Relich M., Banaszak Z. - Reference model of project prototyping problem [in] Foundations of Management - International Journal, Vol. 3, No. 1, 2011, pp. 33-46. 